\title{
University transformation and regional development
}

\author{
Stuart Blume $e^{1,2}$ \\ ${ }^{1}$ Emeritus Professor of Science \& Technology Studies, University of Amsterdam, The Netherlands \\ ${ }^{2}$ Prometeo, University of Cuenca, Cuenca, Ecuador \\ Autor para correspondencia: S.S.Blume@uva.nl
}

Fecha de recepción: 20 de enero 2014 - Fecha de aceptación: 13 de marzo 2014

\begin{abstract}
Faced with government pressure to transform themselves into research institutions, Ecuador's universities confront a major challenge. Based on a review of the English language literature, this paper attempts to pull together some of the things that can be learned from the experiences of other universities, in other countries, that have been required to adopt new missions and roles. The paper argues that such transformations have implications for an institution's structure and governance, but still more fundamentally for its culture. For transformation to be effective, it must involve rethinking existing (and perhaps long-established) ways of doing things, including how and by whom decisions are made, and how students are taught. Links with regional and community organizations need to be developed, because these can provide a valuable catalyst for change.
\end{abstract}

Keywords: Universities, roles, regional development, community demand, organizational culture.

\section{RESUMEN}

Frente a la presión del gobierno para transformarse en instituciones de investigación, las universidades de Ecuador se enfrentan a un gran desafío. Basado en una revisión de la literatura en inglés, este trabajo intenta reunir algunas de las cosas que pueden ser aprendidas de las experiencias de otras universidades, en otros países, a las que se le han requerido la adopción de nuevas misiones y roles. Este documento sostiene que tales transformaciones tienen implicancias para la estructura y el gobierno de una institución, pero todavía más fundamentalmente para su cultura. Para que una transformación sea efectiva, debe tener en cuenta la necesidad de repensar las formas existentes (y quizás establecidas hace mucho tiempo) de hacer las cosas, incluyendo cómo y por quién son tomadas las decisiones, y cómo se enseña a los estudiantes. Vínculos con organizaciones regionales y comunitarias deben ser desarrollados, dado que estos pueden proporcionar un valioso catalizador para el cambio.

Palabras clave: Universidades; papeles: desarrollo regional; demanda de la comunidad; cultura organizacional.

\section{THE CHALLENGES FACING THE UNIVERSITIES}

Like universities in much of the 'Global South', Ecuador's higher education institutions are under pressure to change. Having long emphasized excellence in teaching, government policy now requires the universities to develop new competences in research and postgraduate education. How is this to be done, given that most institutions lack both of staff with research experience and institutional experience in developing and managing research?

Based on a review of the empirical (English language) literature, this paper highlights some potentially useful lessons that can be drawn from the experience of universities in other countries that have faced pressures to change. The paper will suggest that for a university to change itself by 
adopting a new mission or role has implications for the structure, the governance, and the culture of the institution, all of which need to be considered. At the same time links with the region and the community can be of value in stimulating and supporting change.

Pressures on universities to transform themselves can be of very different kinds. Dramatic changes in a country's political system almost inevitably force change on its universities. This was the case, for example, with the collapse of communist regimes in Eastern and Central Europe at the beginning of the 1990s, and the sharp decline in government subsidies which followed (e.g. Eisemon et al., 1995, Morgan and Bergerson, 2000). In South Africa, the end of Apartheid led to radical reform of the country's higher education system (e.g. Fourie, 1999). Geographically nearer, in Chile in the early 1980s the Pinochet military regime cut back state funding of higher education and encouraged privatization (Bernasconi, 2005).

The pressures to which universities are forced to respond are not usually so radical. More commonly, they derive from a gradual change in the role universities are expected to play in society. Inevitably, what this involves depends partly on the traditional role of the university, which in turn reflects a country's history, society and culture. For example, Lewis and Simmons (2010) writing about the Caribbean universities, argue that they failed to develop research activities because Caribbean society historically relied on the importation of ideas and knowledge from outside. On the other hand in the UK, prior to 2004, only institutions conducting research and awarding PhD degrees could call themselves universities. However, Deem (2006) argues that rising costs may mean that many British universities will be required to give up research. In many countries universities traditionally had the function of reproducing social elites: elites which were committed to maintaining the existing order of things and with little interest in knowledge or innovations which could threaten it. Elsewhere, including in much of Latin America, universities traditionally saw themselves as having an essentially critical function. The long social-critical tradition in Latin American universities both allied them with emerging forces for social and economic change and often involved an antagonistic relationship with ruling elites and with industry (Ordorika, 1996 and 2003). However, Arocena and Sutz (2001) suggest that the way Latin American universities conceive of their role in society has changed since the 1980s. Earlier antagonisms toward industry have weakened.

This new wave of more fluid relationships between university, industry and government resulted also from the change in the university perception of its role in society: less emphasis on social criticism and more legitimisation for the specialised participation in knowledge accumulation and in the solution of national problems. One of the indicators of the change of discourse and also of culture is the almost across the board acceptance of the legitimacy of university-industry relations. This pattern was not at all clearly legitimated 20 years ago and the change has to do not only with necessity but also with virtue: helping production to use knowledge more intensively is increasingly seen as a developmental goal that fits well with the Latin American university spirit of social commitment (Arocena and Sutz, 2001).

In the industrialized world the debate is somewhat different, though here too the role of the university has changed considerably in recent decennia. The discussion however differs from that in Ecuador because it does not focus on turning long established teaching institutions into research institutions (though that happened in many countries twenty or thirty years ago). Much of the literature now being produced in Western Europe, North America, and Australasia concerns the emergence of what is generally called the university's 'third mission', or 'third role'. In addition to their traditional teaching and research, universities should also deploy their knowledge resources in the service of society, most particularly of economic growth.

University systems differ considerably in how and how powerfully this new 'third role' is being forced on universities, and institutions differ in how enthusiastically they have accepted it. Still, in much of the world pressures to engage differently with society (and especially the economy) have been multiplying. Tomaney and Wray (2011) point out that universities have not traditionally been seen as 'economic institutions'. 
The literature on the role of universities and regional development (including the emerging critique) has a strongly economistic flavour. In this respect it simultaneously reflects, responds and contributes to the 'instrumentalization of the university'; in other words, the subordination of the university to the goal of local and national competitiveness in the global knowledge economy. During the twentieth century, however, the university had a larger role as a central institution in the project of modernity. The university during this period was typically an actor in nation-building - but this was a cultural project, not merely an economic one. While the modern functions of the university involved the reproduction of existing social inequalities, the university was also a key site for the production of civic and liberal democratic values and embodied 'the ideal of the university as a kind of community', founded on widely cast scholarship speaking to multiple publics and hence more of a cultural institution than an economic asset (Tomaney and Wray, 2011).

Pressures on a university system to change may thus derive from radical changes in a country's political system, or they may derive from more gradual change in societal expectations. Universities have responded to these pressures in very different ways, reflecting not only differences in the nature of the challenge faced but also differences in their specific structures, functioning and cultures.

\section{INSTITUTIONAL RESPONSES - A LITERATURE REVIEW}

The challenges confronting academic institutions in the Global North have largely involved building stronger links with the economy, and it is this which dominates the academic literature. An analysis which assumes that a university has a long research tradition, and which focuses on the integration of economic objectives, might seem to have little relevance for the challenge facing universities in Ecuador. To some extent this is true. It is unlikely that useful lessons can be drawn from studies of the interaction of world-class elite institutions with the research-intensive industries that have grown up around them (Stanford and Silicon Valley for example, or MIT and Boston's Route 128, or Cambridge University and its Science Park). But there is a significant and potentially useful literature in which the practical experiences of universities other than these are described.

For example, Srinivas and Viljamaa (2008) discuss the case of Turku, a medium-sized city in southern Finland, and in particular why and how the city's two universities became involved with the development of a biotechnology industry in the city. They interviewed academic scientists, businessmen, and city officials who had been involved, and they read available policy documents. The picture that emerges is a complex one. External circumstances played a part. Loss of traditional Finnish markets in the USSR after its collapse, coupled with the country's accession to the European Union, had led to a slow decline in Turku's economic base. City authorities therefore became interested in the development of new industries. National science and technology policies also played a role. However the analysis mainly points to the important role played by informal organizations and networks, bringing together senior people from the different sectors. There was no grand strategy to start with, and from the universities' point of view the major incentive to become involved was a decline in their budgets. The networks gradually became formalized, state funds for stimulating science and innovation were obtained, and out of all this emerged 'Bio Turku', a concentration of firms working in the biotechnology, pharmaceutical and life science sector.

Another study of northern Europe focuses on a city not so very far from Turku. Benneworth et al. (2009) studied Lund University in southern Sweden. They looked at three distinctive sets of initiatives, or learning processes, addressed to three different industrial sectors, all of importance to the region: life sciences, information and communication technologies (ICT) and the food industry. The study shows that how Lund University engaged with these different industries differed from one to the other. The university already had well-established research in both informatics and life sciences, and in both these sectors initiatives were strongly supported and influenced by a number of high-tech firms that were already established nearby. The food industry, made up of relatively small firms with low capacity for absorbing research, was quite different. 
The problem Lund University faced in working with the local food industry had to do with the structure of the industry and the industry's need to shift from labor-intensive large scale production of low value-added products to higher value-added products. Facilitating this process presented a particular challenge to the university because knowledge inputs from the university would have to draw on a range of scientific disciplines. A government technology program helped them meet this challenge. Lund University was able to obtain funding for a large-scale strategic innovation project, 'Food Innovation at Interfaces', from a national program because it had already spent years developing contacts with the industry. The program (Food Innovation at Interfaces) represented the culmination of a decade of interactive network-building in Lund around food innovation, creating systemic innovation connections able to mobilize in response to such an opportunity. The project provided funds to realize the potential of a latent innovation network in which $L U$ already played an important role. However, the project also stimulated $L U$ itself because of the different types of knowledge involved in the project and the need for particular relationships to encompass the transfer of many different types of knowledge types, disciplines and bases. In other words, studying questions of importance to the food industry required the university to build new links internally. It became necessary to integrate knowledge-inputs from different disciplines and across departmental boundaries.

Another example described in the literature concerns Waterloo University in Canada (Bramwell and Wolfe, 2008). Here, the relatively young university's success at engaging with industry had less to do with research activity than with how it organized its teaching. Much of the University of Waterloo's success at linking with both local and non-local industry is largely attributable to four well-known characteristics: the ability to attract, retain, and train top calibre graduates and researchers, and to link them with local and non-local employers; the provision of $R \& D$ support to local firms; the interactive exchange of tacit knowledge at both local and global levels; and the active facilitation of entrepreneurial activities. In terms of human capital creation and knowledge transfer, the university performs a critical intermediary function through its Co-operative Education Program that links students directly with firms.

Recognizing the shortage of technical manpower and the growing needs of industry, the university, from its foundation, was going to organize its education in collaboration with industry. The Co-operative Education Program, in which students spend some time working in a company, grew out of this initial commitment. The rotation of students to industry and back to the classroom solidified already tight relations with local industry. The reflexive relationship allows the curriculum to keep up with the ever-changing technological frontiers of industry while industry support of the program funds the acquisition of technology to enhance classroom learning. It was thus that Waterloo became one of the first universities in Canada to enable students to actively explore and make use of innovations in the relatively new field of computing (Bramwell and Wolfe, 2008).

Importantly, a few comparative studies have concluded that forms of engagement between universities and their regions depend both on characteristics of the region and the structure of the universities. Boucher et al. (2003) who studied universities' engagement with their regions in numerous European countries, found that how universities were involved tended to depend on the region. In smaller less central regions, universities often represent a unique repository of knowledge, largely because of the lack of other institutions providing similar services such as governmental research laboratories, social science research centres, and businesses with $R \& D$ departments. Thus the 'enabling' ability of the universities in these regions is greater: universities enjoy a position as vital partners necessary for the success of particular policies and projects. Universities in these regions are better positioned to shape the institutional environment and regional agenda rather than participating in a reactive fashion. In the case of Spain, the influence of universities on the regional policy agenda is less clear in Madrid than in Andalusia, which can be attributed to the increasing number of actors within the regional system of research and higher education located in Madrid.

Rodrigues (2011), drawing on a comparative study of Tampere University in Finland (TUT), Cardiff University in Wales and Aristotle University of Thessaloniki in Greece (AUTh), also concludes that how universities can (best) contribute to regional development - how they (should) interpret their 'third role' necessarily depends on their traditions, expertise, and the legal frameworks 
within which they operate. It is misleading to generalize (or theorize) on the basis of quite specific experiences.

The type, history, openness and work traditions of universities largely influence the state of affairs concerning regional engagement. Invoking the case of TUT, from a technologyoriented university that has assumed, from the very beginning, the aim of contributing to regional industry development, one can expect a more prompt and systematic participation in collaborative initiatives, namely with the world of production. On the opposite side, AUTh, because immersed in a constraining legal framework, and affected by sceptic, even adverse academic mind sets and by the absence of co-operative traditions, though improving, is still facing significant barriers to turn third-mission activities into a successful endeavour. Concomitantly, the organizational change effort is likely to require variable energy, respond to different challenges and acquire different configuration (Rodrigues, 2011).

Responding to the unfavourable legal framework in which the AUTh had to operate, units within the university (such as the Chemical Process Engineering Research Institute) that wanted to engage in collaborative research with industry, but felt restricted by the legal framework, moved out of the university. Clearly this represents an impoverishment of the university. Furthermore, Rodrigues (2011) argues that universities should not simply respond to the research demands of local industry. They must look for ways of building links with industry that nevertheless respect the university's distinctive culture and ethos.

Stimulating universities to engage with local and regional industry has become a priority in many national policies, and universities have generally accustomed themselves to these new expectations. As Benneworth et al. (2009) put it 'Increasing regional demands for universities to realize their potential and capitalize on their academic knowledge base come at a time when universities themselves are becoming more open to the idea of a third mission of socio-economic contribution'.

Among attempts to theorize the changes that have occurred in the integration of academic research with social priorities, two concepts have been particularly influential. One is that of the 'triple helix' (Etzkowitz and Leydesdorff, 1998; Etzkowitz, 2003; Arza and Vazquez, 2010). The Triple Helix thesis is that the potential for innovation and economic development in a knowledge society lies in a more prominent role for the university and in the hybridisation of elements from university, industry and government to generate new institutional and social formats for the production, transfer and application of knowledge. This vision encompasses not only the creative destruction that appears as a natural innovation dynamics, but also the creative renewal that arises within each of the three institutional spheres of university, industry and government, as well as at their intersections' (http://triplehelix.stanford.edu/3helix_concept). The other is the claim that a transition has taken place from discipline-based research (mode 1 research) to research structured by collaboration between scientists and other social actors (mode 2 research) (Gibbons et al., 1994). Many authors assume that because particular trends (like these) have been identified in past developments, they should continue in the future. Assuming that past trends show the way in which policy and practices should evolve, provide rules to be followed in the future, is highly problematic. Nevertheless, the empirical recommendations derived can still be valid and useful, as for example the idea that different kinds of institutions and networks are needed. Hybrid organizations such as intermediaries, innovation and incubation centres, and science parks, allowing each sphere to undertake activities from which they were previously excluded. Such overlapping triple helix forms are manifested by industrial policies seeking to develop an industrial structure based on firm engagement in interorganizational alliances and networks with universities (Huggins and Strakova, 2012).

Karlsen et al. (2012) have described developments in the Basque region of Spain, in particular trying to characterize a transition between the traditional discipline-based way of doing research in the region's universities towards a more collaborative (mode 2) approach. They interpret what happened in terms of interplay between macro processes (creation of new institutional structures) and microprocesses (such as the willingness of individuals to change their ways of working). Two practitioners 
from a large firm and a consultancy in the Basque Country with a background as policy-makers and who were closely related to academia and a Professor at the University of Deusto worked to gain the support of public and private agents in the Basque Country to create an arena where researchers and practitioners would interact to improve 'real competitiveness' through research.

The vision was shared by the university authorities. However, according to these authors its longterm success depended just as much on the attitude of individual staff-members: researchers who appreciated practitioner's experience-based knowledge generated the method and work habits that made the initial bridging evolve into co-generation processes.

Using quantitative data gathered from the Spanish regions in an econometric analysis, Miguélez et al. (2011) reach a qualitatively similar conclusion, but introduce the additional concept of "social capital' (a concept much used in recent sociology). They argue that social capital (the mutual trust, the extent to which norms and values are shared, and the social networks that characterize a society or region as a whole) influences the production of knowledge and the efficacy with which knowledge/research is deployed in innovation.

But how relevant is any of this to universities in the Global South, and to Ecuador's universities in particular? Perhaps the challenges are too radically different. Researchers do not agree as to the relevance of theoretical concepts (such as mode 1, mode 2 or the triple helix) for the concerns of Southern countries and their universities.

In South Africa, the debate about a new form of scholarship has been heavily influenced by the concept of Mode 1 versus Mode 2 knowledge production (Gibson et al., 1994). Their widely recognized work 'The New production of Knowledge. The Dynamics of Science and Research in Contemporary Societies', while not disregarding the importance of Mode 1 knowledge production, appeals for a new form of knowledge production which is transdisciplinary, application-oriented, socially accountable, reflexive and context-sensitive, in other words 'knowledge has to be produced in the context of application involving a much broader range of perspectives' (Gibbons, 2000). Mode 2 knowledge production requires stronger collaboration between academia and a host of other actors, including practitioners, policy-makers and community-based actors (Brown-Luthango, 2013).

However, other authors notice that theories about 'how research is changing' are largely based on experiences in the industrialized world and question their relevance for those now developing. Thus Arza (2010) suggests that the influence of manufacturing industries on university research may not correspond to the real needs of a developing society. First, the socio-economic needs are different. Unlike the usual reality in developed countries, large fractions of the population in developing countries live in poverty. Moreover, the income distribution is highly unequal, and education and health systems are deficient, which perpetuates social inequality. Furthermore, the level of pollution, largely the result of outdated production technologies, is distressing. All these features create specific demands on PROs, which are often not comparable to the demands of economic activity in developed countries. As Mazzoleni and Nelson (2007) claim, the key to catching up is research that is useful for the individual country. Thus, research needs to be oriented to the social needs of users. However, in a context where many technology users are poor, which means that their needs may not be converted into effective market demand, the demand exerted by private firms on PROs may not agree with the needs of the majority (Arza, 2010).

Most of the studies cited above start from the assumption that universities must be pushed to facilitate industrial innovation and competitiveness. How appropriate is this assumption? For one thing, in much of the world regional development involves much more than industrial innovation. Any symbiotic relationship between regional and university development is likely to be more complex. 


\section{UNIVERSITIES IN THE GLOBAL SOUTH}

Over the past 30 years, and with the exception of Central and Eastern Europe countries, the challenges facing universities in the Global North have not come from radical political change. Of course universities have been deeply affected by the rise of neo-liberal thinking and the 'marketization' of public services. But these influences, which have given rise to the processes described earlier, have been gradual, building up over 30 years. Some countries in the Global South, by contrast, have undergone dramatic changes. Universities have tried, or have been obliged, to respond. The Pinochet dictatorship in Chile rapidly reduced state subsidies to universities, some of which responded enthusiastically by raising student fees, generating income by developing consultancy services for industry, and linking staff employment to productivity (Bernasconi, 2005).

In South Africa, by contrast, the end of Apartheid led to demands for a more widely accessible and socially responsive university system, a system which is sensitive to social, political, cultural and economic changes in its environment. Amongst other things such responsiveness implies that higher education should engage with the problems and challenges of the social, political and economic context in which it operates. As far as the research function of higher education is concerned, several innovations are envisaged. These include the emergence of new forms of transdisciplinary knowledge production, the involvement of other research agents in addition to academic researchers, and new forms of accountability by higher education researchers to external constituencies. In the research context, academics will interact with their colleagues in higher education, but also with knowledge producers in a range of other organisations and enterprises. Greater social accountability towards the state and the client in terms of cost-effectiveness, quality and relevance of research programmes is expected of the academic (Fourie, 1999).

An almost invariable characteristic of poor and middle income countries and regions is a lack of demand for research. Because neither public nor private institutions are typically concerned with developing new products or with changing their practices, they have little interest in new ideas. This led Lewis and Simmons (2010), reflecting on the situation in the Caribbean, to argue that a priority for the universities is to convince other institutions, and the society at large, that research can be of value. A consequence of the Caribbean society being historically dependent on the importation of ideas, and of expertise, is that the demand in the region for research-based knowledge is weak, and that consequently little tradition of innovation exists. Perhaps this requires the forging of relationshipscollaboration between the universities on one hand and governments and private industry on the other. The public and private sectors in the Caribbean need to be convinced that it is in their interests to rely on research in their deliberations. The universities probably have to take the initiative here, helping these entities, as well as the public at large, to see the value of research, and joining with them as partners in this.

Research in the Global South should have priorities different from those of Northern research institutions. For example, Sutz (2003), a scholar from Uruguay, has written about the distinctive agenda for research that Latin American universities should adopt. Her agenda concerns above all the eradication of poverty and reduction of inequality. The crucial thing is that social objectives improvements in living and working conditions, poor health, social and economic inequality - should inspire the agenda of university research. The latter stated that universities in Latin America faced particular problems given the research lacked social or political context; the weakness of the institutional frameworks and policies for supporting research; and the preference of scientists to orient themselves to the international scientific community rather than local problems. Arocena and Sutz (2001) give an example from Uruguay in which the university made an important contribution to local industry. It involves the Physics Department of the Faculty of Sciences and the Association of Meat Producers, working on the problem of determining the tenderness of meat through non-disruptive methods. Tenderness is one of the attributes that count when exporting meat to affluent markets, and the usual method of measuring tenderness is to stretch the meat fibber until it breaks: pieces of meat of a sample are removed and sent to external specialised laboratories. The alternative approach proposed by the physicists was a portable device, able to measure elasticity by contact - elasticity being a direct proxy for tenderness, not only giving immediate answers but also allowing the tenderness certification of the totality of the cattle and not only of a sample. The method developed for 
tenderness is now analysed further to find inspiration for devices able to measure other important attributes, like fat content.

Another example given by Sutz (2003) shows how research aimed at industrial innovation can also lead both to durable and productive lines of research, whilst at the same time improving local people's living and working conditions. The Uruguayan economy, as the economy of many countries and regional economies in Latin America, is very dependent on the industrial use of raw materials derived from cattle and sheep, such as milk, meat, wool, and leather. All these industries are heavily polluting, but the causes of pollution vary to some extent. For example tannery pollution is aggravated by the use of metals hazardous to health, chromium in particular. Research began on these issues in the Chemical Engineering Department of the School of Engineering in the Universidad de la Republica in Uruguay about ten years ago. The main concern was to reduce chromium levels in sewage from tanneries. It was important to have access to samples and to make tests in real conditions, and some tanneries were concerned by the problem and willing to cooperate. After achieving success in this project, the engineering team established collaboration with hydraulic engineers and microbiologists to address the water pollution problems involved in textile and meat processing. Aerobic and anaerobic reactors were designed, and some of them were installed successfully in factories that agreed to make the necessary investments. The technical approach used in these projects is being adapted to the environmental problems of urban garbage, a significant proportion of which is buried, which increases dangers of underground water contamination in addition to atmospheric pollution. The research agenda was quite successful, the research team grew attracting young people, and gave rise to postgraduate research projects. Research proposals won support from national agencies. Some firms involved in textiles, meat processing, and tanning collaborated with the research; some problems were solved, and prototypes were developed that performed well. Many academic articles were published in important technical journals.

These examples show how universities in less developed countries and regions can help local industry through their research, even when that industry has no previous involvement with research. Education can also play an important role. New teaching methods, promoting students' curiosity and providing them with opportunities for investigating local problems, can transform a university's relationship with its region. Vinh University in Vietnam was established in 1959 as a teacher training college. It is situated in a peripheral rural region of this poor country. In the mid-1980s, changes began to be made to the country's centrally planned economic system, and later reforms were extended to the country's higher education system. Recognizing the changing objectives and demands of education in the new economy, the Vietnamese government launched a major reform policy in 1993 to upgrade higher education. A key aspect of reform has been the amalgamation of single discipline universities, research institutes, teaching universities and colleges to create a system of national and regional multidisciplinary institutions.

In their study, Ramachandran and Scott (2009) focused principally on the Faculty of Agriculture Forestry and Fishing (FAFF), which has been at the forefront of change in Vietnam. In addition to developing applied research projects, the faculty considered the reform of teaching methods and curricula as imporant for the change strategy. New teaching methods in the FAFF included seminar classes, small group work, multimedia and Power Point presentations (although equipment is still very limited), and independent study, where students are assigned questions and present what they learn in class. With only 30\% of curriculum left to individual institutions, the FAFF uses its share for training in participatory action research (PAR) methods. Course books on Participatory Action Research and on gender analysis were used as teaching and reference materials for the first time in 2004, with future courses planned that will focus on these approaches in more detail. In higher-level courses such as Rural Development Research Methods, students visited rural communities to practice PAR methods, conduct interviews, focus group discussions, and strengths, weaknesses, opportunities and threats (SWOT) analyses on particular problems, and write essays on their experience upon return. The FAFF is also building an apprenticeship programme for senior students to study at the provincial Department of Agriculture and Rural Development.

Since (regional) development involves more than industrial growth alone, it seems possible that there should be other ways in which universities might contribute. Though little studied (most literature focusses on industrial innovation) this does indeed prove to be the case. Universities can 
contribute to the development of non-manufacturing industries such as tourism, creative industries, and social services such as health, social work and education. They can facilitate the enrichment of community life that the creative industries offer (Chatterton, 2000). Doyle reports on a comparative study carried out in different regions of the UK, Australia and Norway. In many of the rural regions studied economic growth was expected to come not from manufacturing industry but from the cultural and creative industries and tourism. For example, in England, 'culture' is linked to heritage, tourism and environmental sustainability. There are art galleries, unique garden projects and an array of festivals, usually held in the warmer summer months so as to attract large numbers of visitors to the region despite the congestion it causes. In the Scottish region, great emphasis was placed on the status of Cultural Capital of Europe in 1990 because it drew visitors in large numbers and helped launch tourism as a new industry. In England, UIB's Creative Industry Incubator provides another example of the role of cultural engagement in the context of business development. The universities have a central role to play in all of these ventures, but cultural engagement is not the catalyst nor cultural development necessarily the aim, but rather the conduit. All the regions provide examples of cultural engagement in the sense of the arts and learning about the arts, but this is often linked to a commercial context as well (Doyle, 2010).

The problems that have to be overcome in community and regional development are typically multiple and complex, involving lack of access to stable employment and to public services such as education and health care, poor and unhealthy living conditions, social inequality. It does appear, however, that researchers are gradually coming to acknowledge that universities can and do play a more complex role in the development of the regions in which they are located.

\begin{abstract}
'The redefinition and broadening of regional policy has at the same time implications for the playing field of the higher education institutions and the expectations they have to live up to. Whereas previously, attention was concentrated around the higher education and research institutions as sources of high-tech innovation and new knowledge-based industries, they are now regarded in a broader perspective, encompassing the whole social fabric of which they are a part. The higher education institutions stand out as interesting partners because they are resourceful actors located in the region, because they operate on all scales, and because they link up with so many realms of society and strands of activity. More and more aspects of the academic enterprise are thus perceived as being significant to the regeneration and transformation of the regions' (Arbo and Benneworth, 2007; quoted by Doyle, 2010).
\end{abstract}

Few studies describe universities attempting to engage with the whole complex of issues involved in community development as perceived from within the community. One example comes from South Africa. It suggests how this might be done, but also how difficult it is. The University of Cape Town (South Africa) established its CityLab program in 2008 as an interdisciplinary applied research program. Six separate CityLabs were set up, two area-based (of which one focusing on Philippi, a lowincome district of the city), and four thematic (concerned with urban flooding, the relationship between urban health and the built environment, urban ecology and climate change). Each was to function for a period of between 18 and 24 months. The Philippi CityLab was intended to be a forum where academics, government officials and civil society organisations based in Philippi, could share knowledge and debate issues in order to develop some collective understanding of development processes in low-income settlements such as Philippi. It was hoped that the interaction would eventually lead to the identification of additional and collaborative activities. In the first year a number of exploratory seminars were held in which academics and other role-players working in Philippi were given an opportunity to present their work. In the second year there was a sharper focus. Meetings and presentations were organized around the specific theme of 'integrated community development'.

The program was regarded as having failed. The community had not been deeply enough involved, and many people felt that researchers had used the program for their own scientific purposes without giving anything to the community in return. Insufficient effort had been devoted to developing mutual trust between the poor and needy residents of the area and the university researchers. In the author's view to have really set about satisfying the needs and expectations of both university and 
community would have required more time, effort and resources. She concludes that the experience of the Philippi CityLab also shows that stakeholders should not be nalve about the time, effort and investment which these kinds of engagements require and the difficulty of establishing, maintaining and sustaining genuine, mutually beneficial university-community collaborations'. Furthermore, a truly engaged scholarship requires a significant transformation of the institutional context within universities in order to not only facilitate and support, but also reward research which seeks closer collaboration between universities and communities (Brown-Luthango, 2013).

Developing a collaborative approach to problem solving in the case of a deprived community such as this differs completely from, for example, the examples of Finnish or Canadian universities engaging with local life sciences or engineering industries given earlier. If we regard these South African and Finnish/Canadian examples as two ends of a continuum, then other examples given (such as those from Uruguay and Vietnam) fall somewhere in between. In all cases new structures, new inter-organizational networks, new teaching methods and curricula seem to have a role to play. Differences reflect what is involved, first, in convincing society (or the community) that new knowledge and skills can be of value to them, and second, building up a relationship of mutual trust.

New missions, new structures, new and different relationships with industry and community, new ways of teaching, can all be seen as innovations in universities' structures and functioning. How do universities set about becoming 'innovative institutions'? Any answer to this question has to consider the ways in which universities are organized and the ways in which decisions are taken.

\section{UNIVERSITY GOVERNANCE AND STRUCTURES}

Radical political change almost invariably results in new laws redefining the way universities are financed, organized, and administered. Structures, processes, and individual academic leaders, seen as compromised by their association with the previous regime, must be replaced. New structures, processes, and forms of governance compatible with the new ideology have to be designed. Prior to the collapse of the Soviet system universities in Central and Eastern European countries were totally controlled by the state. They had no significant research function, since research was carried out in Institutes of the National Academies of Science, separate from the universities. Changes taking place over the past 20 years have involved them in not only developing research competences, but in learning how to organize themselves, plan and budget: functions previously carried out by the state (Morgan and Bergerson, 2000). Not infrequently - in universities just as in other organizations innovation is resisted by elites fearful of possible threats to their status or privileges.

For example, reflecting on the governance of Mexico's National Autonomous University (UNAM) Ordorika (1996) argues that changes in this vast institution have largely involved attempts of traditional academic elites, and more particularly a vast university bureaucracy, to preserve their privileges and continued control of the institution. This author attributes UNAM's problems, over many years, to a lack of academic leadership and legitimacy of governing bureaucracies. These authorities have internalized the external demands for change but have been incapable of outlining a reorganization of academic disciplines, a modernization of goals and tasks, and a democratic reform of governance structures. In their eagerness to maintain control over the institutions of higher education, bureaucracies have prevented faculty and students from conceptualizing and putting into practice these and other kinds of reforms. The vertical and centralized procedures used by university authorities to transform the institution are unable to generate the necessary consensus within the university community. At the same time, the authorities have been unwilling to undertake a process of discussion and negotiation with contesting groups to produce a general agreement about university reform.

The market-thinking that in many countries has forced universities to look for new sources of income and better to serve industry, has also pushed them to behave like businesses, having 'stakeholders' (like shareholders) to whom they must be accountable (Jongbloed et al., 2008). As a result, many universities have abandoned their traditionally collegiate, shared style of decision-making in favour of a more hierarchic managerial model, seen as 'business like' and efficient (Wright and 
Rabo, 2010). In contrast to Ordorika's analysis (1996), the ideologically-based assumption in many countries is that if changes have to be made centralized decision-making is the best way of implementing them. Some of the authors quoted earlier are quite clear that in many universities longestablished practices will need to be changed. For example, Brown-Luthango (2013) suggests that developing research in collaboration with the local community requires universities to adopt an incentive structure that rewards such research. Aracona and Sutz (2001), drawing on the experience of universities in Latin America, suggest that developing new relationships with economy and society requires universities to develop ways of regulating the external activities of staff, so that these activities become integrated into their work at the university. They also suggest that changes to universities' systems of accounting are necessary. In almost all cases, one of the big problems to foster businesslike relationships with the external world was the inadequacy of the university accountancy system. Slow, heavy, subjected to the generic type of controls of the public system, it hampered the reception of external money and the spending of it according to the timetable established in the contracts with private firms.

It might seem that changes in incentive structures and accounting practices, not to mention recruitment and promotion policies, can best be managed by a powerful central administration. Other studies, however, cast doubt on this conclusion. Increasing centralization can lead to conflict, since strict hierarchy conflicts with traditional ideals of academic freedom and collegiality which many academic staff still hold. Introduction of a more managerial style can generate conflict between university management and the academic staff which objects to lack of participation and consultation. Drawing on her experience of such a conflict as a senior manager in Massey University (New Zealand) Meyer (2007) argues that ways of reconciling managerial efficiency with collegiate debate have to be found. Senior management of a university cannot institute major changes in the face of widespread resistance from academic staff. In line with Meyer's conclusion, various authors argue that 'institutional culture' is critical in any transformation of a university.

Transformation of higher education institutions is therefore not only about changes in the composition of staff and students, or changes in governance structures or course content. Essentially, it is about the transformation of the organisational culture and the development and acceptance of new, shared values. This can only be achieved through fundamental changes in the mind set ('cognitive transcendence') of all stakeholders and role-players, amongst which academic staff requires particular attention (Fourie, 1999).

Learning is fundamentally a social act that can best take place under conditions where there is community sharing and support. This fundamental notion can underpin the architecture of research culture. Individuals do not have necessarily to go it alone. Research culture can be fostered if it is a shared value, and if those within that culture are prepared to collaborate when necessary in the solution of problems of common interest (Lewis and Simmons, 2010).

Gunasekera (2006) reaches a similar conclusion on the basis of interviews with 60 teachers and administrators in Australian universities located in economically and socially diverse regions of the country. His study was designed to see what current rhetoric regarding 'engagement' meant to individuals. He found that it meant different things to different people, that there was typically a lack of incentives to get involved (it didn't help promotion), that universities didn't try to coordinate what their different faculties did. A successful initiative by one faculty was rarely known to or influenced other faculties. Individuals differed in how they related the idea of 'engagement' with their self-image as teacher/researcher. Gunasekara concludes: The evidence presented suggests that university managers and policy-makers need to pay close attention to the way new initiatives are designed and explained. Too often, new initiatives are introduced that make sense to a small group of managers, but which are not seen as convincing by those who are expected to deliver the benefits of the new programme (ibid.).

In practice, members of a university community might well disagree about the desirability of major changes to the institution, whether this implies adopting a 'third mission' or requiring that 
university teachers engage in research. Tomaney and Wray (2011) surveyed staff opinion in Monash University, in the state of Victoria in Australia. They found that whilst senior staff agreed that the university hadn't interacted much with businesses in the region, they did not agree as to whether this should be a mission for the university.

Whilst a minority of senior management attributed the lack of interaction to the behaviours of industry, claiming that it 'does not see the university as being business orientated' (ibid.) or that businesses 'just don't know how to get into this place' (ibid.), one senior respondent in the university was concerned that despite academics being 'expected to work with agencies from government through to industry' there has been very little training of academics to do that; the average academic wouldn't have a clue about how you go about it' (senior manager 5). As such it would be likely that academics would 'negotiate bad deals, be late with their deliverables and are naive' (ibid.). By contrast, a local stakeholder suggested that businesses are 'not always aware of the benefits or praxis' (senior local government official 3) of the research or activities that are undertaken in Victorian universities, whilst another felt that Monash needed to 'open themselves up and be more experimental' (senior local government official 4). Such views held by those both inside and outside Monash University highlight a 'misalignment of cultures' (senior manager 5), and the fact that 'a lot of work needs to be done in helping business, industry and community to gain a better understanding of our worlds, our culture and how we operate and vice versa' (ibid.).

For a transformation process, such as 'becoming a research institution', to proceed smoothly and effectively it needs to have support within the institution. That means that teaching and other staff, as well as students, should have the opportunity of discussing the proposed changes. Change is likely to be resisted if there is a widespread sense of threat (whether to jobs, to security, to income, to educational quality or autonomy). Ideally the proposed changes will be in line with the shared sense of what the university stands for: its traditions and values.

In addition, some of the studies quoted above (e.g. Bernasconi, 2005) suggest that a decentralized management structure has certain advantages. Giving more autonomy and decision-making power to individual faculties should allow them to develop initiatives fitted to their specific (and almost certainly very varied) opportunities and constraints. A number of successful transformation processes described in the literature took place at the level of an individual faculty.

For example, in the early 1990s, teacher training in New Zealand was moved from specialized colleges of education into the universities. Teaching staff then found themselves in an environment in which they were required to conduct research, though few had any experience (Hill and Haigh, 2012). Based on interviews with academic leaders and staff in the University of Auckland and elsewhere, Hill and Haigh conclude that a 'community of research practice' has to be created. As one interviewee explained: We tried to get experienced researchers to lead teams and then associate less experienced with those more experienced staff [and learn to research] just by being involved in a research project and learning how to write research reports. Learning about all those research techniques like sampling ... and participating with research connected to the profession. Learning in a community of practice is about being immersed in the norms of the research environment, where the everyday talk and practice is imbued with what is valued as research. These research leaders believed that seeing oneself as a researcher as well as a teacher educator needs constant encouragement, reinforcement and practice.

What is involved in establishing such a 'community of research practice', or research culture, is likely to differ from one faculty to another, even in the same university. So how can it be established at the faculty level? One way is to establish a dedicated research centre. This is what the Faculty of Social Work at the University of Toronto did in the early 1990s, when it committed itself to developing research.

In 1995 the Faculty of Social Work established the Centre of Applied Social Research (CASR) as the major catalyst and incubator for research. CASR's mandate is to conduct 
applied social research related to the effectiveness of social work practice interventions, programs, social policies, and resource allocation. CASR provides an organizational infrastructure to link faculty scholarship with community research needs and graduate student research interests CASR provides concrete assistance for faculty members in terms of keeping them informed about research funding opportunities, assisting with the completion of grant applications and ethics clearance, networking with colleagues across the university, hiring research assistants, and managing the financial aspects of grants (Shera, 2008).

\section{MANPOWER POLICY ALSO PLAYED A CRUCIAL ROLE}

New faculty hired during this period of change had extensive training in research and a long-term commitment to research and scholarship as a primary focus of their academic career. New faculty were provided with one course release per year until tenure and a senior faculty mentor to ensure the development of a robust program of research. Most of the faculty increased their productivity in research and scholarship, and the submission and success rates for external grants increased significantly. A few faculty were, however, not interested in moving in this direction. In these situations, we were able to work with individuals to consider early retirement or job alternatives (Shera, 2008).

Reflecting on the Faculty's experiences, which have led to a changed organisation with a productive research staff, Shera draws a number of important lessons:

- Building an organization's capacity to increase research productivity takes time, requires continuity of leadership commitment, and must be comprehensive if it is to have an impact on organizational culture.

- When and where possible, use external forces to create a sense of urgency and increase motivation to change by providing support and incentives, hiring new faculty who are supportive of the mission, and assisting those who are not to find acceptable alternatives.

- Establish a research office or center that provides faculty support and acts as an incubator of new research projects and research partnerships with the practice community. Strive to create additional research centers and research chairs to act as catalysts in specific areas of practice.

- Create research partnerships with other faculties, universities, and community service organizations, but do so developmentally, not taking on too much at one time. When creating research partnerships with community agencies, custom tailor the agreement and focus on the unique strengths and areas for development that are required by using a wide range of contextappropriate strategies.

- Integrate the advancement agenda with the overall strategy for building capacity and productivity in research. Create partnerships with the private sector to leverage additional funds to support chairs, research centers, and research projects.

- Establish a research office or center that provides faculty support and acts as an incubator of new research projects and research partnerships with the practice community.

The lessons which Shera (2008) draws from this Social Work Faculty's experience provide an appropriate introduction to the conclusions of this review. 


\section{CONCLUSIONS}

What can we learn from the studies summarized here? The challenges facing the universities in these studies have much in common: in each case, they involve the adoption of new roles and missions. On the other hand, the circumstances under which the universities operated, their resources and constraints, differed enormously. It is therefore not possible to derive a comprehensive, universally applicable answer to the question of 'how do universities transform themselves'. However, even though the precise details will depend on specific institutional resources and constraints, it seems that in planning for change universities need to consider the following sets of issues:

- Managerial, manpower, and educational practices;

- The structure of the organization;

- The organizational culture;

- How links with the community can be developed and used to support change.

\section{Practices}

In almost all cases described in the literature, adoption of a research mission by what was previously a purely teaching institution has involved changes to human resource management (recruitment and promotion policies). When looking to recruit new academic staff, the universities looked only for people with $\mathrm{PhD}$ degrees and some research experience. This was especially the case for more senior vacancies. Incentives, possibly in the form of extra salary or reduced teaching load, may have to be offered (whether to reward research performance per se, or collaborative research involving outside partners specifically). It may be necessary to consider possibilities of offering early retirement, or other work, to teachers who cannot identify with the new mission. Consideration needs to be given to the integration of teachers' external activities into their work at the university, or at least the registration of these activities (though clearly no loss of income should be involved). The possible need for changes to the university's accounting system may have to be considered.

Changing the university's mission must involve some rethinking of its ways of teaching. A research university must teach in ways that promote students' curiosity and provide them with transferable skills, such as team working, use of the literature, analyzing problems. They need to 'learn how to learn' so as to be equipped to seek out and accommodate new knowledge in the course of their professional lives. It may be desirable to provide them with opportunities for investigating local problems in the course of their study.

\section{Structure}

Different faculties of the same university almost certainly have different opportunities for change and face different constraints. Whether because of the age-profile of its staff, or existing links with outside organizations, or for other reasons, one faculty may be more willing, or more able, to innovate than another. Innovating - introducing new missions - may therefore be easier on a faculty-by-faculty basis than for the university as a whole. Although the literature offers no clear conclusions regarding how much autonomy faculties should have in recruitment policies, control of budgets, organization of teaching etc., it is clear that this is something that needs to be considered. Of course the distribution of responsibilities between a university's central administration and its faculties may be determined by law and so beyond the university's power to change. But it should not be assumed that decisionmaking structures appropriate to the university as it was are also appropriate to the university as it wishes to be.

Research is always a collective undertaking, and even experienced researchers cannot work effectively alone. Whether at the level of the individual faculty, or a cluster of faculties, or the university as a whole, researchers require regular contact with each other in a supportive environment. This might best be accomplished by providing a physical space in which each researcher is expected to carry out his/her research tasks, and in which he/she can interact regularly with other researchers. Here, a research culture can be nurtured: one which, it is to be hoped, will gradually diffuse outwards to the university as a whole. 
However, many of the questions which research should address, particularly those emerging from interactions with the environment, will not correspond to any single discipline. They are likely to require the collaboration of researchers from different faculties. A university's research organization will not necessarily, or not completely, correspond to the faculty structure in which education is offered.

\section{Culture}

The transformation of a university requires more than changes in the composition of staff and students, or changes in governance structures or the content of teaching programmes. Ultimately it requires a transformation of the organisational culture, and the development and acceptance of new, shared values, and a new professional identity. What this means in practice is that for such a process - for example 'becoming a research institution' - to proceed smoothly and effectively it needs to have support within the institution. That means that teaching and other staff, as well as students, should have the opportunity of discussing the proposed changes. Change is likely to be resisted if there is a widespread sense of threat (whether to jobs, to security, to income, to educational quality or autonomy). Ideally the proposed changes will be compatible with the shared sense of what the university stands for: its traditions and values.

\section{Links with community and region}

A university's links with its community and its region can provide an important stimulus both to research and to structural innovation. However in much of the world neither region nor community provide this stimulus because local institutions lack previous engagement with universities or research. This means that a priority task for universities, in dialogue with local economic and social institutions, is to establish what research can do for them, to identify issues of common interest, and to develop relations of mutual trust and confidence. This may take some time, and may not be easy.

Despite the emphasis in the literature on links with economic institutions, and despite the fact that building links may well proceed more smoothly with the larger more advanced business corporations in a region, the university's potential contribution to regional and community development is broader. The university can contribute to the development of non-manufacturing industries such as tourism, and to improvement of the social services available to people with varying needs, values and resources. This contribution will be realized both through applied research and through innovative teaching methods.

In the long term, the fundamental marker of success may well be the creation of 'social capital': the mutual trust, the extent to which norms and values are shared, and the social networks that characterize a society or region as a whole, and on which both university and region can draw. In the short term, it is important to appreciate that transformation of a university must involve reconsideration not only of its structure, but also of established educational practices, of the way in which decisions are taken, of the expectations of individual academic staff. It is not something than can be accomplished quickly. It has to be done on the basis of a strategic, multi-year plan, to be developed on the basis of widespread consultation. All those having a stake in the university, including its students, and including representatives of its community and its region should be encouraged to participate in this consultation.

\section{BIBLIOGRAPHY}

Arbo, P., P. Benneworth, 2007. Understanding the regional contribution of higher education institutions: A literature review. A research report prepared for the OECD Institutional Management in Higher Education Programme: The contribution of higher education to regional development. OECD Education Working Papers, No. 9, OECD Publishing, 79 pp. Downloaded from $h t t p: / / d x . d o i . o r g / 10.1787 / 161208155312$ in November 2013. 
Arocena, R., J. Sutz, 2001. Changing knowledge production and Latin American universities. Res. Policy, 30, 1221-1234.

Arza, V., 2010. Channels, benefits and risks of public-private interactions for knowledge transfer: Conceptual framework inspired by Latin America. Sci. Publ. Policy, 37(7), 473-484.

Arza, V., V. Vazquez, 2010. Interactions between public research organisations and industry in Argentina. Sci. Publ. Policy, 37(7), 499-511.

Benneworth, P., L. Coenen, J. Moodysson, B. Asheim, 2009. Exploring the multiple roles of Lund University in strengthening Scania's regional innovation system: Towards institutional learning? Eur. Plan. Stud. , 17(11), 1645-1664.

Bernasconi, A., 2005. University entrepreneurship in a developing country: The case of the P. Catolica Universidad de Chile, 1985-2000. High. Educ., 50, 247-274.

Boucher, G., C. Conway, E. van der Meer, 2003. Tiers of engagement by universities in their region's development. Reg. Stud., 37, 887-897.

Bramwell, A., D.A. Wolfe, 2008. Universities and regional economic development: The entrepreneurial university of Waterloo. Res. Policy, 37, 1175-1187.

Brown-Luthango, M., 2013. Community-university engagement: The Philippi City Lab in Cape Town and the challenge of collaboration across boundaries. High. Educ., 65, 309-324.

Chatterton, P., 2000. The cultural role of universities in the community: Revisiting the universitycommunity debate. Environ. Plann., A 32(1), 165-181.

Deem, R., 2006. Conceptions of contemporary European universities: To do research or not to do research? Eur. J. Educ., 41(2), 281-304.

Doyle, L., 2010. The role of universities in the cultural health of their regions: Universities' and regions' understandings of cultural engagement. Eur. J. Educ., 45(3), 466-480.

Eisemon, T.O., I. Mihailescu, L. Vlasceanu, C. Zamfir, J. Sheehan, C.H. Davis, 1995. Higher education reform in Romania. High. Educ., 30(2), 135-152.

Etzkowitz, H., 2003. Innovation in innovation. The triple helix model of university-industrygovernment relations. Soc. Sci. Inform., 42, 293-337.

Etzkowitz, H., L. Leydesdorff, 1998. The endless transition: A 'triple helix' of university-industrygovernment relations. Minerva, 36(3), 203-208.

Fourie, M., 1999. Institutional transformation at South African universities: Implications for academic staff. High. Educ., 38(3), 275-290.

Gibbons, M., 2000. Universities and the new production of knowledge. In: Kraak, A. (Ed.), Changing Modes. Human Science Research Council Pretoria, South Africa, 38-55.

Gibbons, M., H. Nowotny, C. Limoges, S.Schwartzman, M. Trow, 1994. The new production of knowledge: The dynamics of science and research in contemporary societies. SAGE Publications Ltd., London, 192 pp.

Gunasekara, C. 2006. Leading the horses to water: The dilemmas of academics and university managers in regional engagement. J. Sociol., 42, 145-162.

Hill, M.F., M.A. Haigh, 2012. Creating a culture of research in teacher education: Learning research within communities of practice. Stud. High. Educ., 37(8), 971-988.

Huggins, R., L. Strakova, 2012. Knowledge-based economic development in emerging regions: Policy issues and implications in the Balkan peninsula. Reg. Stud., 46(7), 961-975.

Jongbloed, B., J. Enders, C. Salerno, 2008. Higher education and Its communities: Interconnections, interdependencies and a research agenda. High. Educ., 56(3), 303-324.

Karlsen, J., M. Larrea, J.R. Wilson, M-J. Aranguren, 2012. Bridging the gap between academic research and regional development in the Basque Country. Eur. J. Educ., 47(1), 122-138.

Lewis, T., L. Simmons, 2010. Creating research culture in Caribbean universities. Int. J. Educ. Dev., 30, 337-344. 
Mazzoleni, R., R.R. Nelson, 2007. Public research institutions and economic catch-up. Res. Policy, 36, $1512-1528$.

Meyer, L.H., 2007. Collegial participation in university governance: A case study of institutional change. Stud. High. Educ., 32(2), 225-235.

Miguélez, E., R. Moreno, M. Artís, 2011. Does social capital reinforce technological inputs in the creation of knowledge? Evidence from the Spanish regions. Reg. Stud., 45(8), 1019-1038.

Morgan, A.W., A.A. Bergerson, 2000. Importing organizational reform: The case of lay boards in Hungary. High. Educ., 40(4), 423-448.

Ordorika, I., 1996. Reform at Mexico's National Autonomous University: Hegemony or bureaucracy. High. Educ., 31(4), 403-427.

Ordorika, I., 2003. Power and politics in university governance: Organization and change at the Universidad Nacional Autonoma de Mexico. RoutledgeFalmer, New York \& London, 290 pp. Downloaded from http://works.bepress.com/ordorika/17 in September 2013.

Ramachandran, L., S. Scott, 2009. Single-player universities in the South: The role of university actors in development in Vietnam's North Central Coast Region. Reg. Stud., 43(5), 693-706.

Rodrigues, C., 2011. Universities, the second academic revolution and regional development: A tale (solely) made of 'Techvalleys'? Eur. Plan. Stud., 19(2), 179-194.

Shera, W., 2008. Changing organizational culture to achieve excellence in research. Soc. Work Res., $32,375-380$.

Srinivas, S., K. Viljamaa, 2008. The emergence of economic institutions: Analyzing the third role of universities in Turku, Finland. Reg. Stud., 423, 323-341.

Sutz, J., 2003. Inequality and university research agendas in Latin America. Sci. Technol. Hum. Val., 28(1), 52-68.

Tomaney, J., F. Wray, 2011. The university and the region: An Australian perspective. Int. J. Urban Regional, 35(5), 913-931.

Wright, S., A. Rabo, 2010. Anthropologies of university reform. Social Anthropology/Anthropologie Sociale, 18(1), 1-14. 